\title{
New Strategy to Monitor and Assess Laboratory Biosafety Programs
}

\author{
Heather N. Meeks ${ }^{1}$, Betiel H. Haile ${ }^{2}$, Ngozi A. Erondu², Lisa Ferland ${ }^{2}$, Meeyoung Park ${ }^{2}$ and \\ Scott J. McNabb*2, 3
}

'Defense Threat Reduction Agency, Basic \& Applied Sciences, Fort Belvoir, VA, USA; '2Public Health Practice, LLC, Atlanta, GA, USA; ${ }^{3}$ Hubert Department of Global Health, Emory University, Rollins School of Public Health, Atlanta, GA, USA

\section{Objective}

To develop a toolset to monitor and assess laboratory biosafety program performance and cost

\section{Introduction}

Laboratory biosafety - a component of biosecurity - has specific elements that together, comprise a facility's capability to both protect employees and the surrounding public and environment. Measuring these elements permits assessment and the costing of program-specific safety interventions. In the absence of a strategy and toolset, we developed a conceptual framework and toolset that monitors and assesses laboratory biosafety programs (LBPs) and provides useful information (e.g., return on investment [ROI]) for decision makers.

\section{Methods}

We conducted academic and open source literature reviews of LBPs and affiliated organizations laboratory manuals to identify objectives, goals, and indicators. These findings were aligned to laboratory biosafety-specific inputs, activities, outputs, and outcomes to create a strategic, conceptual framework (logic models) used to assess performance and measure the cost and ROI. Indicators were identified in existing literature or developed and mapped to the logic model elements.

\section{Results}

Six logic models were created: laboratory biosafety, biosurety, procedural, biocontainment, information security, and training. The laboratory biosafety logic model served as the overall framework for the remaining five sub-logic models. We also established a database containing 161 indicators mapped to each of the logic model elements.

\section{Conclusions}

We developed a strategic framework that monitors and evaluates LBPs. While evaluation of cost-impacts in LBPs provides business intelligence for resource planning, this integrated approach also provides information about gaps. We plan to pilot this toolset and refine indicators using principal component analysis.

\section{Keywords}

Laboratory biosafety; Evaluate Laboratory; program performance

\section{Acknowledgments}

Defense Threat Reduction Agency, Basic \& Applied Sciences

\section{References}

1. Bakanidze L, Imnadze P, Perkins D. Biosafety and biosecurity as essential pillars of international health security and cross-cutting elements of biological nonproliferation. BMC Public Health. 2010;10 Suppl 1:S12.

2. Organization WH. International Health Regulations (2005) IHR Monitoring Framework: Checklist and Indicators for Monitoring Progress in the Development of IHR Core Capacities in States Parties. Geneva; 2010.

3. Carr K, Henchal EA, Wilhelmsen C, Carr B. Implementation of biosurety systems in a Department of Defense medical research laboratory. Biosecurity and bioterrorism : biodefense strategy, practice, and science. 2004;2(1):7-16. Epub 2004/04/08.

4. Garaigordobil M. Evaluation of a program to prevent political violence in the Basque conflict: effects on the capacity of empathy, anger management and the definition of peace. Gac Sanit. 2012. Epub 2012/01/31.

5. Jahrling P, Rodak C, Bray M, Davey RT. Triage and management of accidental laboratory exposures to biosafety level-3 and -4 agents. Biosecurity and bioterrorism : biodefense strategy, practice, and science. 2009;7(2):135-43. Epub 2009/07/29.

6. Le Duc JW, Anderson K, Bloom ME, Estep JE, Feldmann H, Geisbert $\mathrm{JB}$, et al. Framework for leadership and training of Biosafety Level 4 laboratory workers. Emerging Infectious Diseases. 2008;14(11):1685.

7. Lewis M, Development CfG. Governance and corruption in public health care systems: Center for Global Development; 2006.

8. Losinger WC, Bush EJ, Hill GW, Smith MA, Garber LP, Rodriguez $\mathrm{JM}$, et al. Design and implementation of the United States National Animal Health Monitoring System 1995 National Swine Study. Preventive veterinary medicine. 1998;34(2-3):147-59.

9. Miller SR, Bergmann D. Biocontainment design considerations for biopharmaceutical facilities. Journal of Industrial Microbiology \& Biotechnology. 1993;11(4):223-34.

10. Murray CJL, Evans DB. Health systems performance assessment: World Health Organization; 2003.

\author{
*Scott J. McNabb \\ E-mail: scottjnmcnabb@emory.edu
}

